\title{
Mechanical Properties of Aluminum Composites Reinforced with PAN- and Pitch-Based Short Carbon Fibers
}

\author{
Kazunori Asano \\ Department of Mechanical Engineering, Faculty of Science and Engineering, Kindai University, Higashiosaka 577-8502, Japan
}

Pure aluminum and AC8A aluminum alloy matrix composites, which were reinforced with PAN- and pitch-based short carbon fibers, were fabricated by squeeze casting, then the composites were exposed to a heat treatment. The effects of the fiber types, composition of the matrix, and heat treatment on the mechanical properties of the composites were investigated. The fibers were in a random planar arrangement in the composites. Although the aluminum carbide was formed due to the reaction between the PAN-based fiber and pure aluminum during the casting process, there was no reaction products near the PAN-AC8A, pitch-pure aluminum and pitch-AC8A interfaces. Although the ultimate compressive strength of the PAN-based fiber composite was greater than that of the pitch-based fiber composite under every condition, the strength of the PAN-based fiber composite degraded due to the heat treatment when pure aluminum was used as the matrix. Examination of fracture surface indicated that the lower reinforcing effect of the pitch-based fiber would be due to delamination at the boundary between the highly-developed graphite crystallites in the fiber. A hardness measurement of the fibers in the composites using a nano-indenter revealed that the interfacial bonding strength between the pure aluminum and PAN-based fiber degraded due to the heat treatment. [doi:10.2320/matertrans.M2017023]

(Received January 20, 2017; Accepted March 28, 2017; Published April 28, 2017)

Keywords: aluminum, carbon fiber, composite, squeeze casting, interfacial reaction, mechanical properties

\section{Introduction}

Aluminum alloys, having a low density and good oxidation resistance, have been widely used for industrial applications such as in the aerospace, automobile and electronics sectors. These applications often require a high-temperature strength. Since the strength and rigidity of the aluminum alloys at elevated temperature are poor, their use as a heat-resistant material is limited. Reinforcing the alloys with the nonmetallic materials, such as the ceramic fibers or whiskers, is one of the methods for improving the high-temperature properties of the alloys. Carbon fibers would be one of the best reinforcements for improving the properties because they have a low density, high strength, high rigidity and low thermal expansion ${ }^{1-3)}$. Carbon fibers are roughly divided into the polyacrylonitrile (PAN)-based one and the pitch-based one. Pitch-based carbon fibers can be produced from either coal tar or petroleum pitch. Mesophase pitch-based carbon fibers have a higher elastic modulus and thermal conductivity than the PAN-based carbon fibers due to the structure in which the planar graphite molecules are highly oriented in the longitudinal direction ${ }^{4)}$. Casting techniques, such as the melt infiltration process, have been widely used for fabricating the carbon fiber-reinforced aluminum composites ${ }^{5-9)}$. Some researchers ${ }^{8-12)}$ reported that the PAN-based carbon fiber easily reacted with the aluminum melt and produced a mechanically and chemically unstable $\mathrm{Al}_{4} \mathrm{C}_{3}$ at the fiber-matrix interface during the casting process. According to these reports, the pitch-based carbon fiber was more stable than the PAN-based carbon fiber in the aluminum melt. The less reactivity of the pitch-based carbon fiber is considered to be due to its highly-developed graphite crystallites ${ }^{10)}$; the heterogeneous nucleation of the $\mathrm{Al}_{4} \mathrm{C}_{3}$ is associated with surface defects on carbon fibers, such as exposed edges of graphite basal planes that exhibit carbon atoms with uncompensated high-energy electron bonds ${ }^{13,14)}$. In addition, the degree of graphitization of the fibers determines the fiber's reactivity to nucleation of the $\mathrm{Al}_{4} \mathrm{C}_{3}{ }^{15)}$. Thus, fibers with a high degree of graphitization (containing highly-oriented basal planes with few exposed edges) and a smooth surface with little topography are ideal for hindering the nucleation of carbides, due to their lack of surface defects ${ }^{11)}$. It has also been reported that the addition of silicon to aluminum suppresses the interfacial reaction between the carbon (graphite) and matrix ${ }^{11,12)}$. This reaction could occur not only during the melt infiltration, but also during the subsequent heat treatment (when the matrix is the heat treatment strengthened type) and/or in use under a high temperature environment. Li et $a{ }^{8}{ }^{8)}$ reported that the heat treatment after the squeeze casting promoted the $\mathrm{Al}_{4} \mathrm{C}_{3}$ formation and degraded the mechanical properties of the PAN-based fiber/pure aluminum composites. Unlike the PAN-based fiber, not many researchers have considered the mechanical properties of the pitch-based carbon fiber-reinforced aluminum composite. In particular, there are few reports about the effects of the randomly-oriented short fibers on the mechanical properties of aluminum. Therefore, the effects of the carbon fiber types (PAN-based or pitch-based), matrix composition and heat treatment on the mechanical properties of the aluminum have not been sufficiently discussed in a manner in which they are related to one another.

In the present study, pure aluminum and high silicon aluminum alloy were selected as the matrices, and they were reinforced with the PAN-based and pitch-based short carbon fibers by squeeze casting. The effects of the carbon fiber types, matrix composition and heat treatment on the interfacial microstructure and mechanical properties of the composites were comprehensively investigated.

\section{Experimental Procedure}

The 99.99 mass\% pure aluminum and JIS-AC8A aluminum alloy (Al-12Si-1Mg-1Cu-1Ni) were used as the matrix metals.

Two kinds of short carbon fibers, the PAN-based and the pitch-based milled fibers were used as reinforcements. The properties of the fibers are listed in Table $1^{1-3)}$. The most sig- 
nificant difference between these fibers can be seen in the elastic modulus values. The scanning electron micrographs of the as-received fibers and fibers in the preforms are shown in Fig. 1. These two fibers were obtained from different companies as close to the same size as possible in order to reduce the size effect on the properties of the composites.

Prior to the fabrication of the composite, the fiber preforms were fabricated as follows. The fibers were dispersed using careful agitation in an aqueous medium containing polyvinyl alcohol (PVA) as an organic binder. Dewatering was conducted by press forming, followed by drying at $373 \mathrm{~K}$ for 3 hours to drive off any residual free water and to obtain the bond strength among the fibers due to the PVA. The preform had a 50-mm diameter and 15-mm thickness. The fiber volume fraction in the composite was controlled at $30 \mathrm{vol} \%$.

The composites were fabricated by squeeze casting. The preform was horizontally placed in the permanent mold, then heated at $673 \mathrm{~K}$ with the mold. The pure aluminum melt at $1063 \mathrm{~K}$ or the AC8A alloy melt at $973 \mathrm{~K}$ (130 K higher than their liquidus temperatures) was poured into the mold, then a pressure of $40 \mathrm{MPa}$ was quickly applied and maintained until solidification of the melt was complete. During the mold heating and/or melt infiltration, the residual PVA in the preform was decomposed due to gasification. The thickness of the composite was approximately $15 \mathrm{~mm}$, which is equal to that of the preform before the infiltration. This indicated that the infiltration was successful without any preform contraction or deformation.

A solution treatment was applied to the AC8A alloy and its composites for $4 \mathrm{~h}$ at $783 \mathrm{~K}$, then water-cooled and aged at $443 \mathrm{~K}$ to obtain the aging curves. The pure aluminum matrix

Table 1 Properties of carbon fibers ${ }^{1-3)}$.

\begin{tabular}{ccccccc}
\hline & $\begin{array}{c}\text { Density } \\
\left(\mathrm{Mg} / \mathrm{m}^{3}\right)\end{array}$ & $\begin{array}{c}\text { Length } \\
(\mu \mathrm{m})\end{array}$ & $\begin{array}{c}\text { Diameter } \\
(\mu \mathrm{m})\end{array}$ & $\begin{array}{c}\mathrm{CTE} \\
\left(\times 10^{-6} \mathrm{~K}^{-1}\right)\end{array}$ & $\begin{array}{c}\text { Tensile } \\
\text { Strength } \\
(\mathrm{MPa})\end{array}$ & $\begin{array}{c}\text { Elastic } \\
\text { Modulus } \\
(\mathrm{GPa})\end{array}$ \\
\hline PAN & 1.76 & 130 & 7 & -0.4 & 3430 & 230 \\
\hline Pitch & 2.20 & 150 & 9.7 & $-1.2 \sim 0$ & 3530 & 940 \\
\hline
\end{tabular}

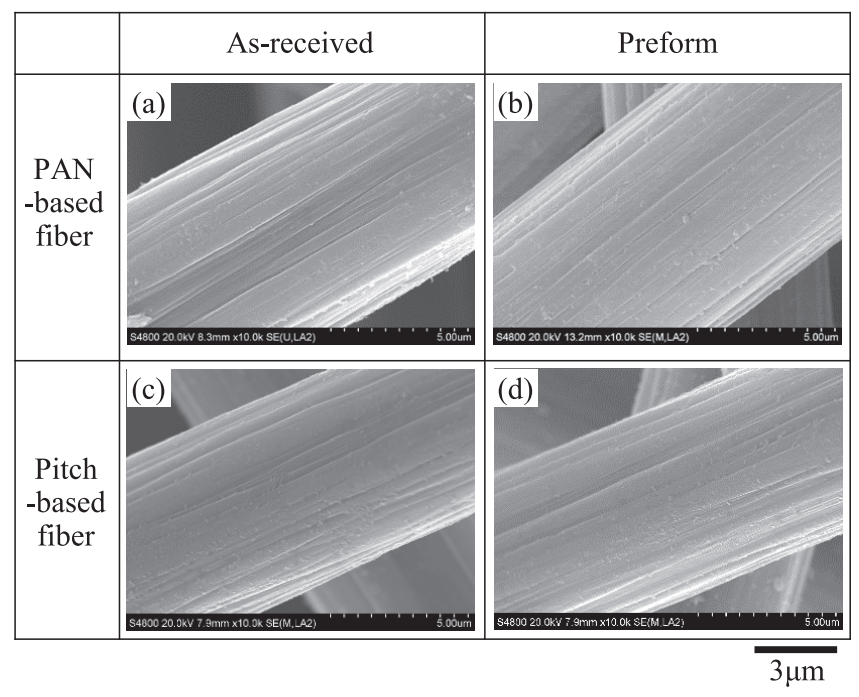

Fig. 1 Scanning electron micrographs showing the surface condition of (a) (c) as-received fibers and (b)(d) fibers in the preforms. composites were exposed to a heat-treatment at $573 \mathrm{~K}$ for $24 \mathrm{~h}$ to investigate the effect of the heat treatment on the microstructure and mechanical properties.

The distribution of the carbon fibers in the composites was examined by optical microscopy. The microstructure in the vicinity of the interface was observed by transmission electron microscopy. In addition, the composite was soaked in sodium hydroxide in order to dissolve the aluminum matrix, then the fibers in the composite were extracted in order to investigate the condition of the extracted fiber surface by scanning electron microscopy.

The hardness of the as-cast and aged specimens was measured using a Vickers hardness tester under a load of $98 \mathrm{~N}$ and a holding time of $15 \mathrm{~s}$. Hardness of the fibers in the composites was measured using a nano-indenter with a load of $20 \mathrm{mN}$ and a holding time of $20 \mathrm{~s}$ in order to evaluate the fiber-matrix interfacial bonding strength.

Compressive test pieces of 8-mm diameter and 12-mm height were machined from the composites, as shown in Fig. 2. A compressive test was performed in the parallel and vertical directions (denoted $\mathrm{P}$ and $\mathrm{V}$ directions, respectively) at ambient temperature and $523 \mathrm{~K}$. The crosshead speed was $2.5 \times 10^{-5} \mathrm{~m} / \mathrm{s}$.

\section{Results and Discussion}

\subsection{Microstructure and hardness}

Figure 3 shows the optical micrographs of the as-cast composites in the parallel (P) and vertical (V) sections to the pressed plane in the squeeze casting. Due to the press-forming in the preform fabrication process, the fibers, observed as the black phase in the micrographs, were in a planar-dimensionally random arrangement in the composites. No difference in the arrangement feature between the two composites was observed.

Figure 4 shows the transmission electron micrographs in the vicinity of the fiber-matrix interface in the as-cast composites. The interfaces between the PAN-based fiber and pure aluminum was rough and another phase other than the matrix and fibers was observed (indicated by the arrow in Fig. 4(a)). The EDX analysis showed that this phase consisted of $\mathrm{C}$ and $\mathrm{Al}$, indicating that this phase was $\mathrm{Al}_{4} \mathrm{C}_{3}$ which was formed by the reaction between the pure aluminum melt and the PANbased fiber during the squeeze casting. The $\mathrm{Al}_{4} \mathrm{C}_{3}$ was not clearly observed near the interface between the PAN-based fiber and as-cast AC8A alloy, as shown in Fig. 4(b). Since the

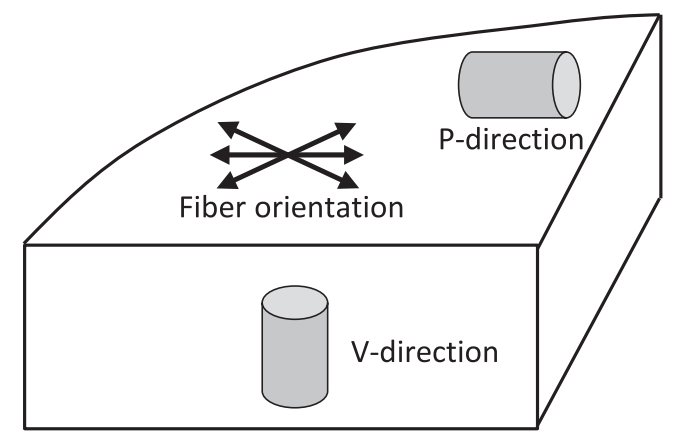

Fig. 2 Schematic illustration of sample position in the squeeze-cast ingot. 


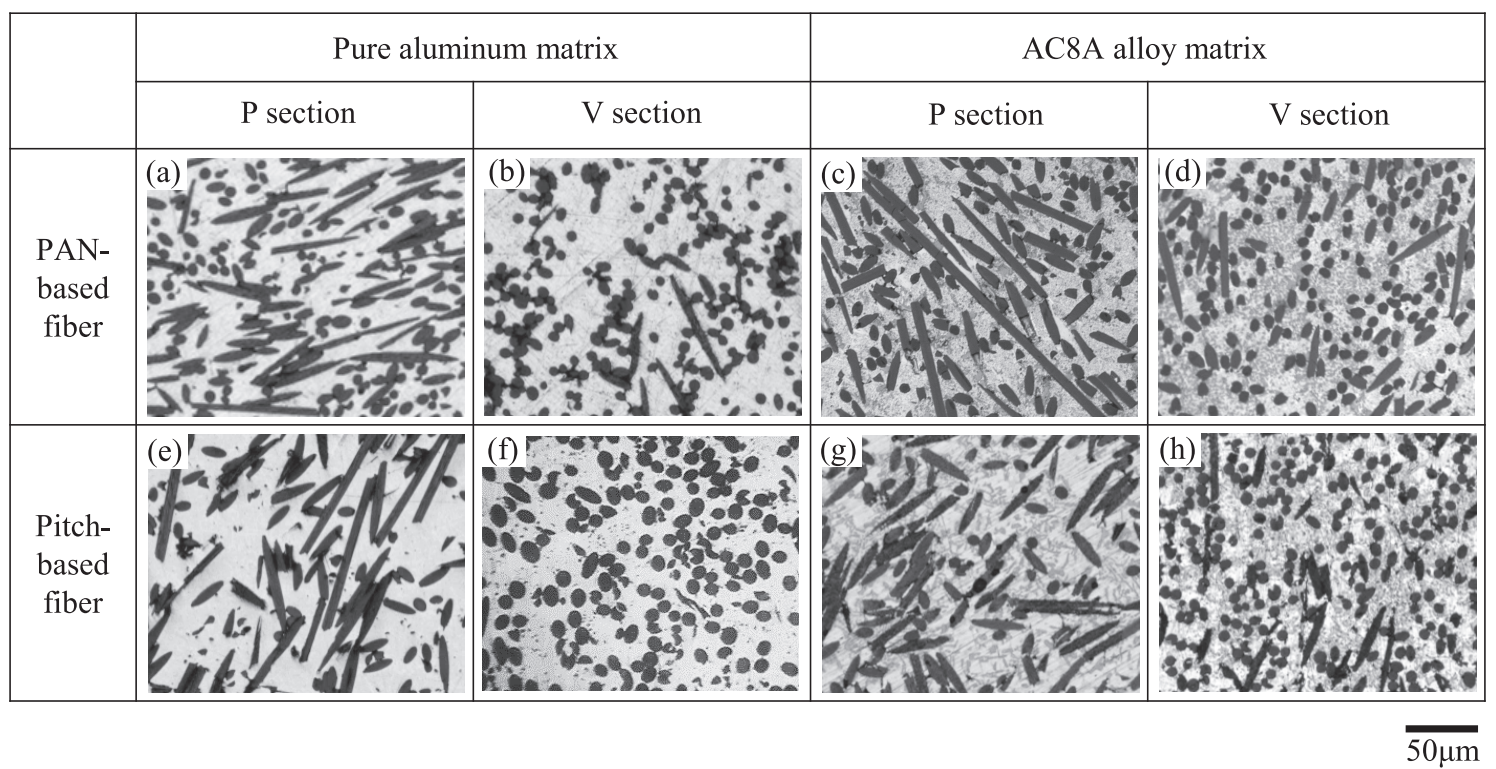

Fig. 3 Optical micrographs of as-cast composites.

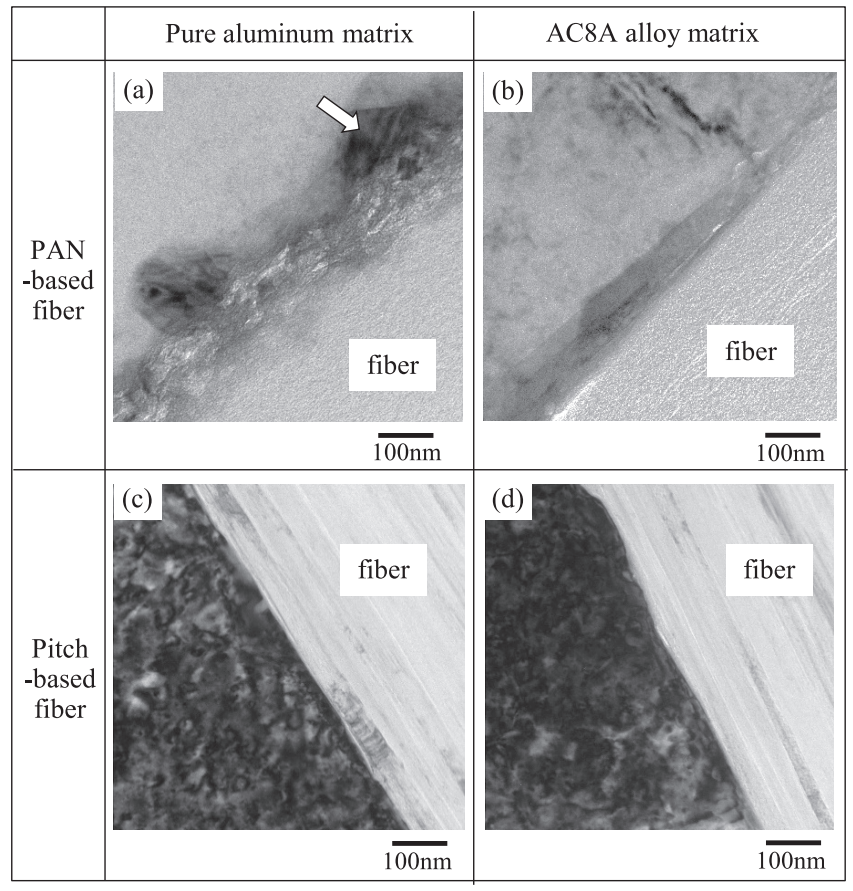

Fig. 4 Transmission electron micrographs in the vicinity of the interface between matrix and fiber in the as-cast composites.

silicon content in the AC8A alloy used as the matrix in the present study was 12 mass $\%$, it can be said that the results obtained from Fig. 4 support the previous reports ${ }^{11,12)}$, which have already been mentioned in the introduction. In contrast, the $\mathrm{Al}_{4} \mathrm{C}_{3}$ was not observed in the pitch-based fiber composites and the interfaces were smooth even though the pure aluminum was used as the matrix (Fig. 4(c)). In this case, no difference in the interfacial feature between the pure aluminum and AC8A alloy matrices was observed, as shown in Figs. 4(c) and (d). As stated in the introduction, it was reported that the pitch-based carbon fiber is more stable than the PAN-based carbon fiber in the aluminum melt ${ }^{8-12)}$, and the results obtained from Fig. 4 also support these reports. Figure 4 also shows that the graphite crystallites are highly developed in a pitch-based fiber (Figs. 4(c) and (d)), while the alignment of the crystallites was not clearly observed in a PAN-based fiber (Figs. 4(a) and (b)).

The aging curves of the unreinforced AC8A alloy and its composites are shown in Fig. 5. The unreinforced alloy showed the peak hardness at the aging time of $6 \mathrm{~h}$, while the composites showed the peak at $4 \mathrm{~h}$; fiber-reinforcement decreased the time required to attain the peak aging. This would be attributed to the precipitation of phases, such as $\mathrm{Mg}_{2} \mathrm{Si}$, on the dislocation which was introduced by the thermal expansion mismatch between the fibers and matrix, as previously reported ${ }^{16,17)}$. Hereinafter, the specimens, which were aged under the condition to attain the peak hardness, are denoted as T6 specimens. Figure 5 also shows that the hardness of the AC8A alloy decreased by the fiber-reinforcement and the hardness of the pitch-based fiber composite was lower than that of the PAN-based fiber composite.

Figure 6 is SEM images showing the surface condition of the carbon fibers extracted from the pure aluminum composites. Fine unevenness was observed on the entire surface of the PAN-based fiber extracted from the as-cast pure aluminum composite (Fig. 6(a)). As shown in Fig. 1, the unevenness was not observed on the fiber and the surfaces were smooth for the as-received fibers or the fibers in the preform. On the other hand, Fig. 4(a) represents that the reaction between the fiber and pure aluminum melt roughened the fiber surface. These facts indicated that the unevenness was formed due to the interfacial reaction. Although the unevenness were also observed on the fiber surface extracted from the heat-treated composite (Fig. 6(b)), the heat treatment did not change significantly its appearance. They were not observed on the surfaces of the pitch-based fibers (Figs. 6(c) and (d)), and the surfaces seem to be the same as that of the as-received fiber or in the preform shown in Fig. 1.

Figure 7 shows SEM images of the carbon fibers extracted from the AC8A alloy composites. No trace marks or fiber 


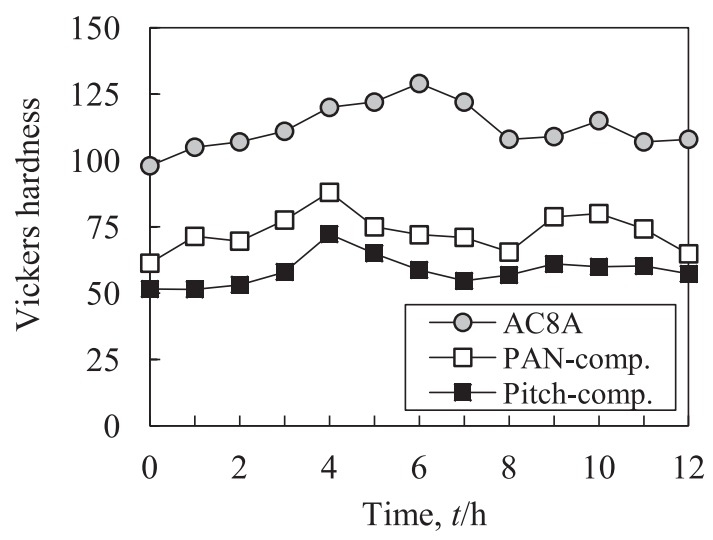

Fig. 5 Aging curves of the unreinforced AC8A alloy and composites.

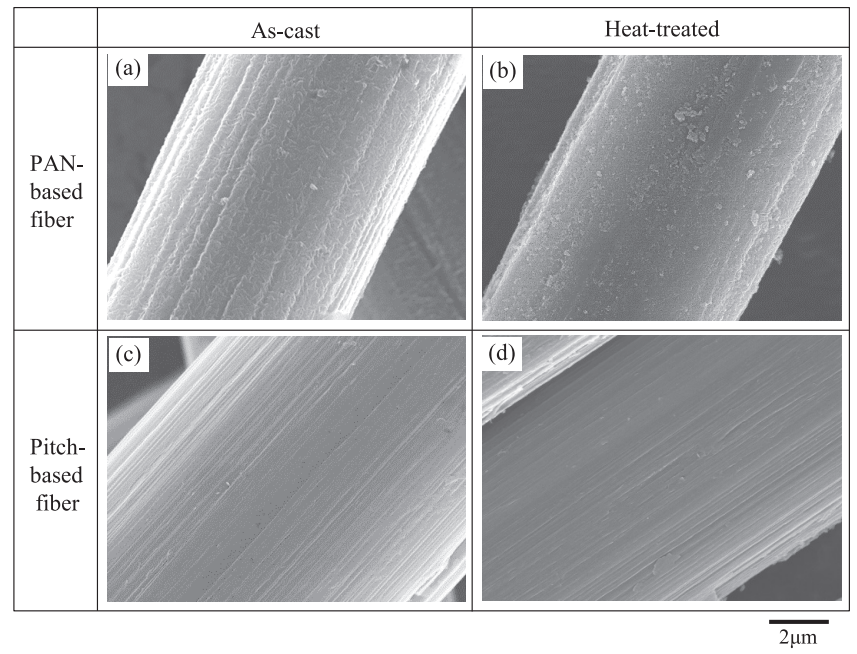

Fig. 6 Scanning electron micrographs showing the surface condition of carbon fibers extracted from the pure aluminum composites.

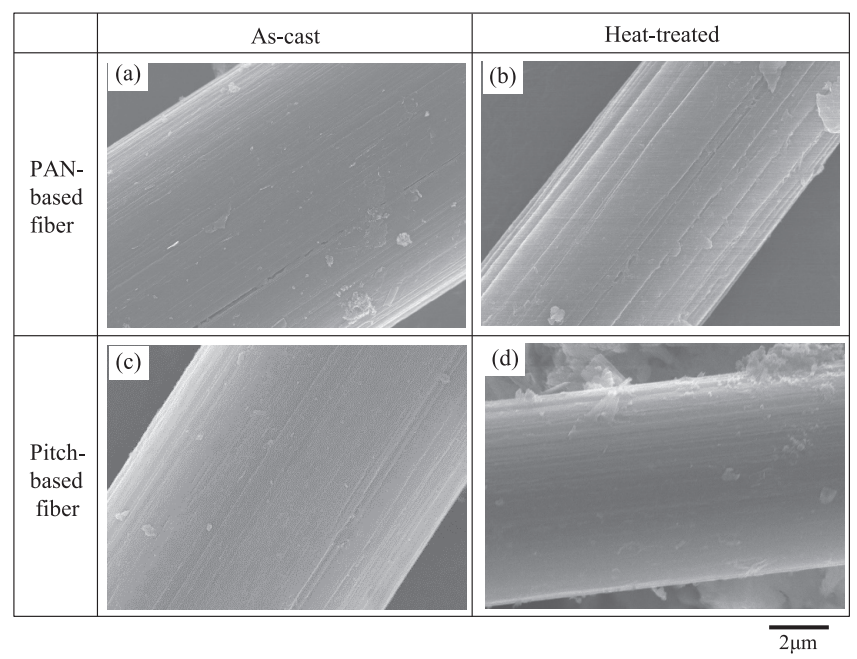

Fig. 7 Scanning electron micrographs showing the surface condition of carbon fibers extracted from the AC8A alloy composites.

damage was observed on every fiber, and the T6 treatment did not affect the surface appearance.

Figure 8 shows the results of the hardness measurements on the fibers in the composites. In every composite, the mean values of the hardness of the PAN-based fiber in the composites were much higher than those of the pitch-based fiber, and the scatter in the hardness values of the PAN-based fibers was greater than that of the pitch-based fibers. For the pure aluminum matrix (Figs. 8(a) and (b)), the scatter in the values of the PAN-based fibers increased, and the mean values decreased due to the heat treatment. For the AC8A alloy matrix (Figs. 8(c) and (d)), the scatter in the values of the PAN-based fibers was less than that for the pure aluminum matrix, and mean values did not change due to the T6 treatment.

\subsection{Compressive properties}

Figure 9 shows the compressive stress-strain curves of the unreinforced metals and composites at ambient temperature. When the compressive load was applied to the as-cast pure aluminum composites in the P direction (Fig. 9(a)), they fractured at a strain of about $14 \%$, while the unreinforced pure aluminum did not show a fracture point. The ultimate compressive strength of the PAN-based fiber composite was greater than that of the pitch-based fiber composite. The strength of the PAN-based fiber composite slightly decreased by the heat treatment, while the curves of the unreinforced pure aluminum and pitch-based fiber composite were similar to those without any heat treatment (Fig. 9(b)). For the as-cast AC8A alloy matrix (Fig. 9(c)), the resistance to deformation of the composites was lower than that of the unreinforced AC8A alloy and they fractured at a strain of about $10 \%$ or less. Although the T6 treatment improved the strength of the unreinforced AC8A alloy and its composites, the reinforcing effect was not obtained as well as in as-cast condition (Fig. 9(d)). The strength of the composites in the $\mathrm{V}$ direction was slightly greater than that in the P direction (Figs. 9 (e) to (h)).

At $523 \mathrm{~K}$, the ultimate compressive strength of every specimen was lower than that at ambient temperature, as shown in Fig. 10. For every matrix and heat treatment condition, the strength of the PAN-based fiber composite was greater than that of the pitch-based fiber composite. As well as for at ambient temperature, the ultimate compressive strength of the PAN-based fiber/pure aluminum composite slightly decreased by the heat treatment (Figs. 10(b) and (f)). Unlike at ambient temperature, the reinforcing effect of the PAN-based fiber was clearly observed in the as-cast AC8A alloy (Figs. 10(c) and (g)).

Figure 11 shows the typical examples of the appearance of the test pieces of the composites after the compression test. Cracks in the diagonal direction to the compressive direction are observed in all the composite test pieces.

Figure 12 shows the compressive fracture surfaces in the $\mathrm{V}$ direction of the as-cast composites at ambient temperature. Although the clean fiber surface or grooves left by the fibers were occasionally observed on every surface, many fractured fibers were observed on the fracture surfaces of the PANbased fiber composites (Figs. 12(a) and (b)). On the other hand, very thin fibers, which were probably formed due to the delamination longitudinally to the fiber, were often observed on the fracture surfaces of the pitch-based fiber composites (Figs. 12(c) and (d)). These thin fibers would be the graphite crystallites, which were already mentioned, and the delamination in the fiber indicates that the fiber-strength in the direc- 

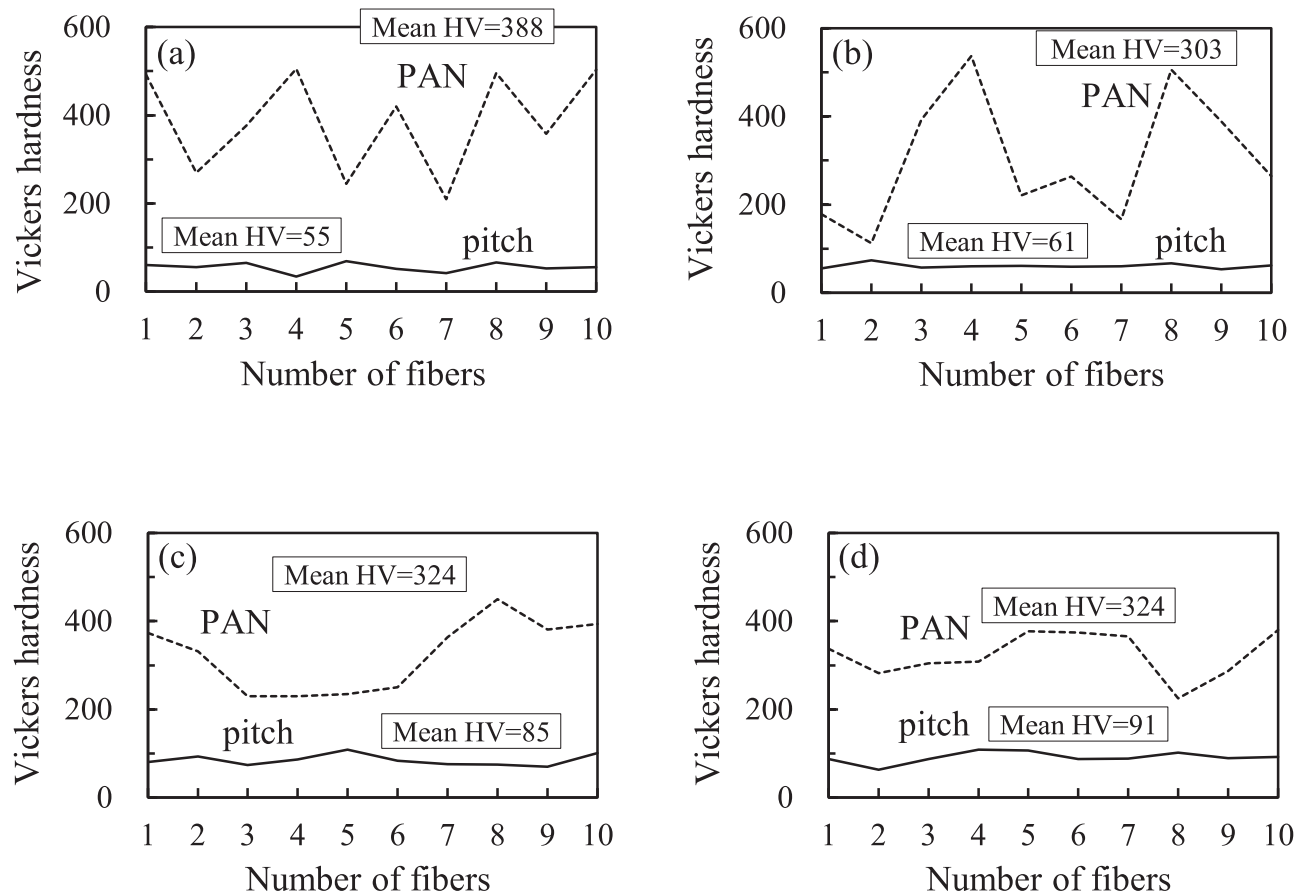

Fig. 8 Variation in the hardness-value of the fibers distributed in the composites. (a) As-cast pure aluminum, (b) Heat-treated pure aluminum, (c) As-cast AC8A alloy, (d) T6-treated AC8A alloy.

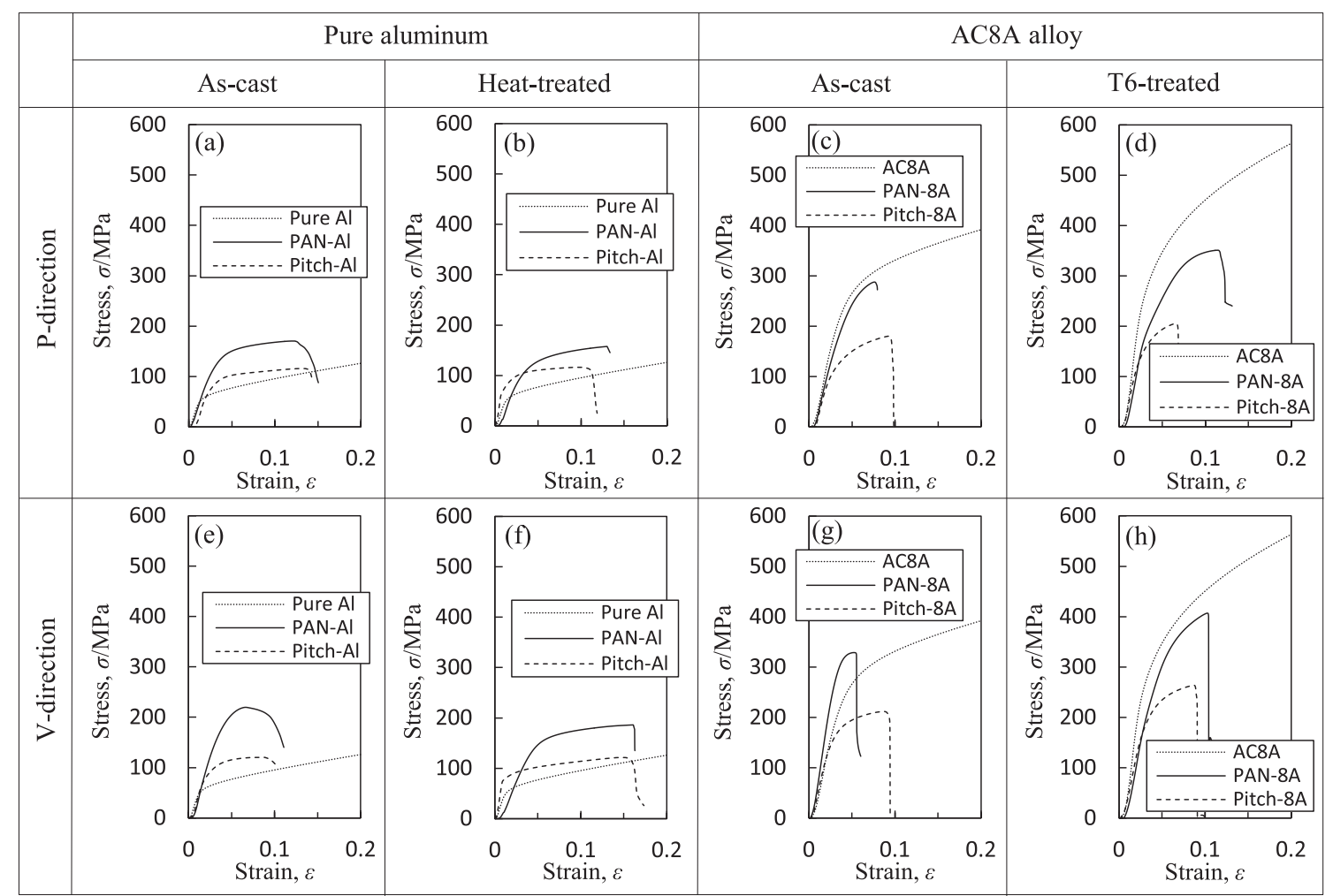

Fig. 9 Compressive stress-strain curves of unreinforced metals and composites at ambient temperature.

tion perpendicular to the stress direction is low.

A similar tendency was observed in the $\mathrm{P}$ direction, at $523 \mathrm{~K}$ and in the heat-treated composites.

\subsection{Effects of fiber-reinforcement on compressive prop- erties}

As shown in Fig. 4(a), $\mathrm{Al}_{4} \mathrm{C}_{3}$ was formed at the interfaces between the PAN-based fiber and pure aluminum. Etter et $a l .{ }^{11)}$ illustrated that the flexural strength of the graphite/aluminum composites was not affected by the $\mathrm{Al}_{4} \mathrm{C}_{3}$ formation. 


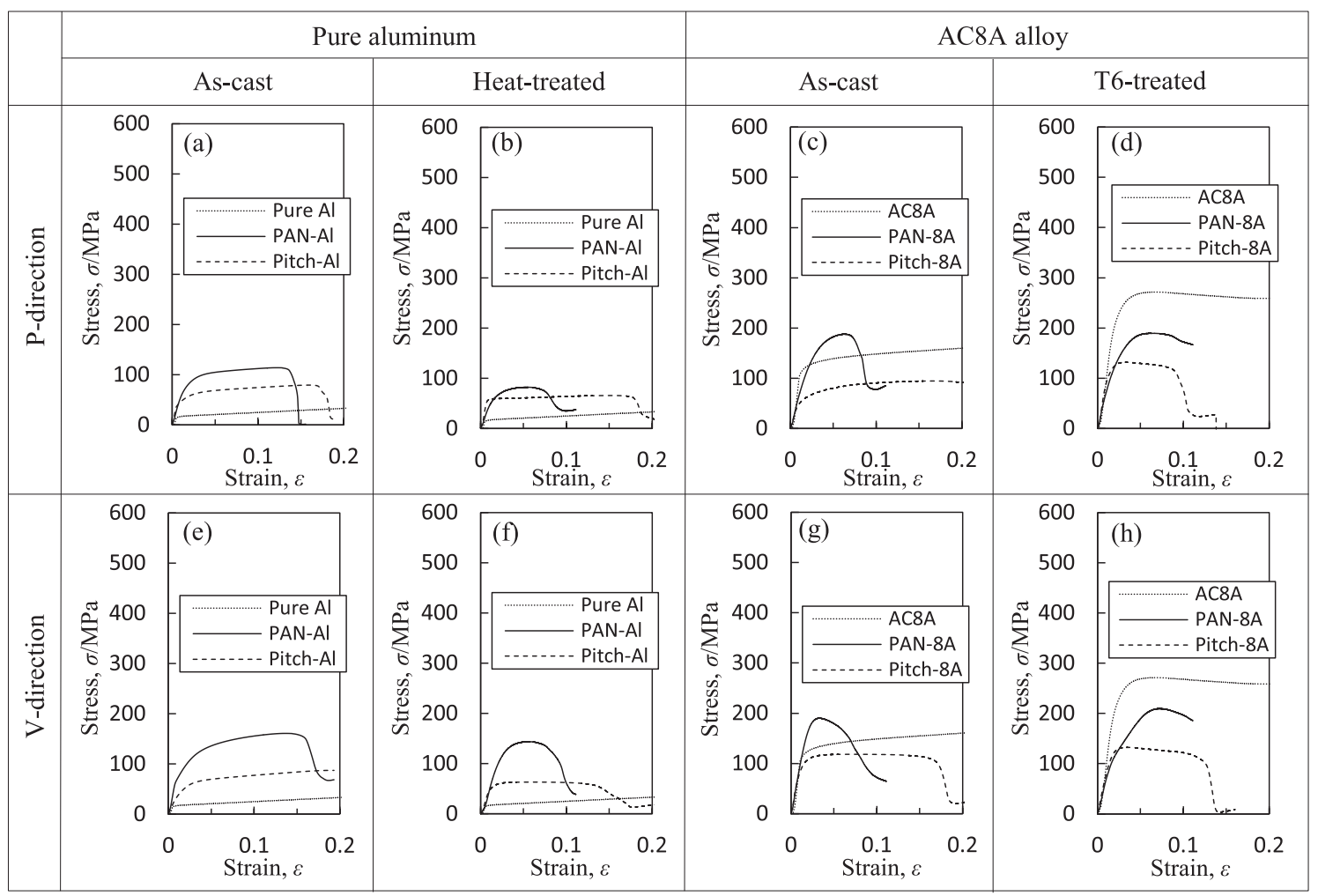

Fig. 10 Compressive stress-strain curves of unreinforced metals and composites at $523 \mathrm{~K}$.

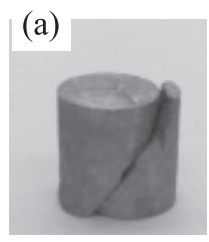

PAN-pure Al at AT (P)

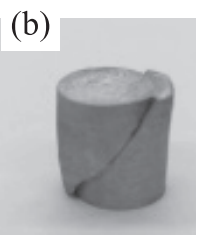

PAN-pure Al at AT (V)

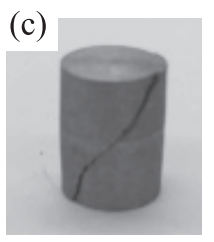

PAN-AC8A at $\mathrm{AT}(\mathrm{V})$ (d)

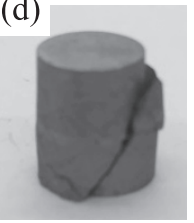
at $523 \mathrm{~K}(\mathrm{~V})$
Pitch-AC8A

Fig. 11 Appearance of the test pieces of the composites after compression test. AT in the figure represents the ambient temperature.

The author ${ }^{18)}$ reported that $\mathrm{Al}_{4} \mathrm{C}_{3}$ was formed at the interface between the PAN-based fiber and pure aluminum, and this made the interfacial bonding strong enough to suppress the interfacial sliding during the thermal cycle. Yamada et al. ${ }^{9)}$ also reported that the $\mathrm{Al}_{4} \mathrm{C}_{3}$ formation increased the interfacial strength which led to the high compressive strength but low flexural strength of the PAN-based fiber/aluminum alloy composite. They also reported that the $\mathrm{Al}_{4} \mathrm{C}_{3}$ formation produced cracks in the compression test pieces generated in the diagonal direction, indicating the strong interfacial bonding. In the present study, the cracks are generated in the diagonal direction to the compressive direction for all the composite test pieces, as shown in Fig. 11. In addition, the clean fiber surface or grooves left by the fibers were not frequently observed on the fracture surfaces of the composites, as shown in Figs. 12 (a) and (b). These results indicated that the interfacial bonding between the PAN-based fiber and matrices in the present study was strong enough to transmit the stress between the fiber and matrix. As shown in Figs. 9 and 10, rein- forcing with the PAN-based fiber increased the resistance to deformation of the pure aluminum at every temperature. However, the ultimate compressive strength of the PANbased fiber/pure aluminum composite decreased by the heat treatment. As shown in Fig. 8, the scatter in the hardness values of the PAN-based fibers in the pure aluminum increased due to the heat treatment. Mizumoto et al. ${ }^{19)}$ reported that the specimen with a weak bond interface showed a significant scatter in the hardness values of the reinforcement (particle) in the aluminum composites, which may reflect the intrinsic nature of the weak bond interface where the particles would be slightly moved upon loading due to the weak bond and the existence of voids near the interface. Li et al. ${ }^{8)}$ reported that approximately $1 \% \mathrm{Al}_{4} \mathrm{C}_{3}$ enhanced the interface bonding, but increasing the content of $\mathrm{Al}_{4} \mathrm{C}_{3}$ to over $3 \%$ after heat treatment degraded the mechanical properties of the PAN-based fiber/aluminum composites. Although the amount of $\mathrm{Al}_{4} \mathrm{C}_{3}$ in the composites was not measured in the present study, these results indicated that the heat treatment would degrade the interfacial bonding between the PAN-based fiber and pure aluminum matrix in the present study.

Although the ultimate compressive strengths of the AC8A alloy composites were higher than that of the pure aluminum composites, the reinforcing effect of the PAN-based fibers was not obtained for the AC8A alloy at ambient temperature, and the effect was clearly observed only in the as-cast condition at $523 \mathrm{~K}$, as shown in Figs. 10(c) and (g). Although the tensile strength of the fibers (see Table 1) are quite greater than that of the AC8A alloy at ambient temperature (see Fig. 9), the fiber strength values in the Table 1 are those in the longitudinal direction of the fiber. Since the short fibers were randomly oriented in the composite, the reinforcing effect 


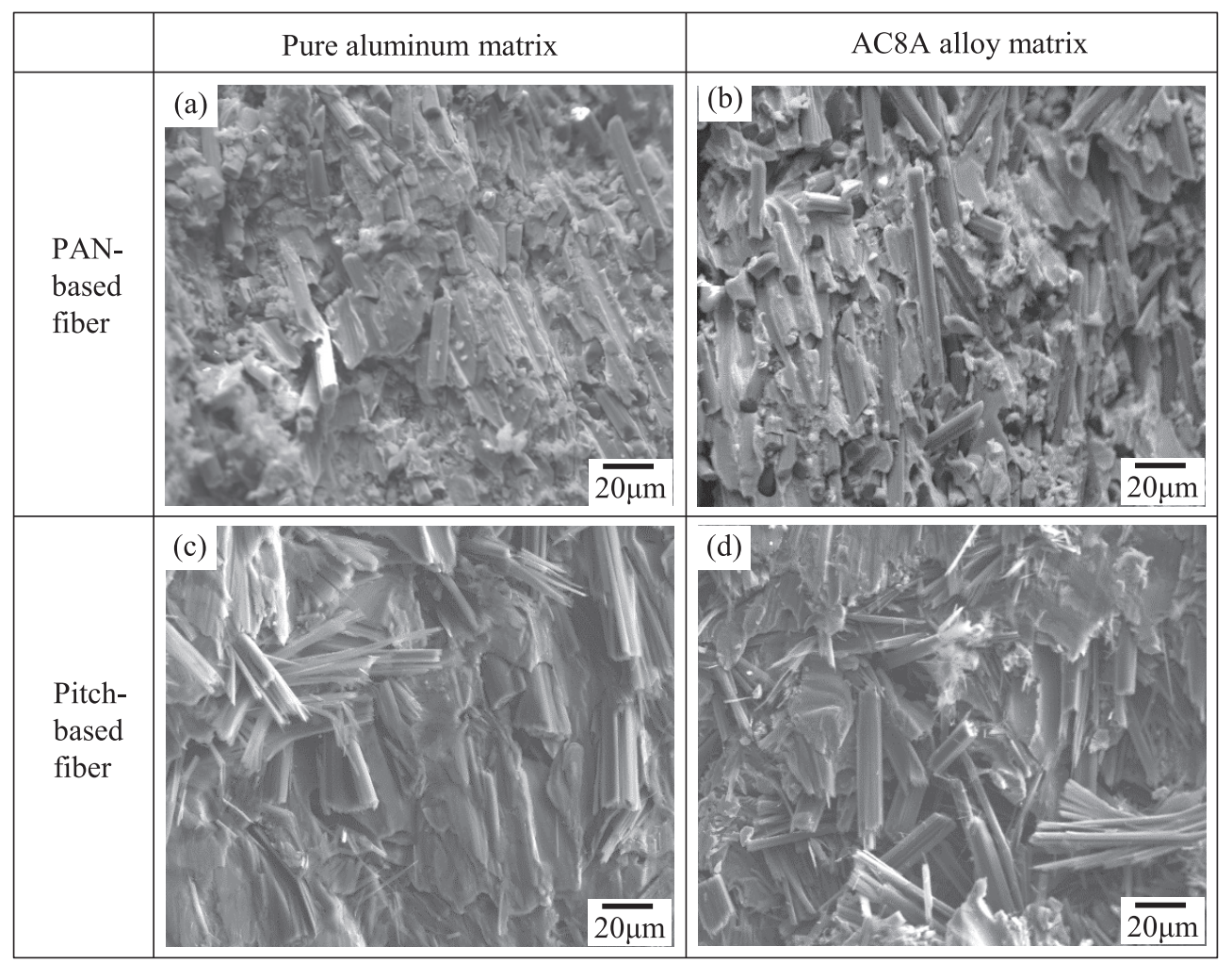

Fig. 12 Compressive fracture surfaces in the $\mathrm{V}$ direction of the as-cast composites at ambient temperature.

would be reduced by the fibers oriented perpendicular to the stress direction; it is difficult to obtain the reinforcing effect when the matrix has a high strength. These facts would lead to the results that the reinforcing effect of the PAN-based fibers was not obtained in the AC8A alloy matrix at ambient temperature. On the other hand, Figs. 9 and 10 showed that the degradation in strength of the composites due to the T6 treatment did not occur for the PAN-based fiber/AC8A alloy composites. This result would be supported by Figs. 7(a)(b) and $8(\mathrm{c})(\mathrm{d})$; the T6 treatment did not promote the reaction and degrade the interfacial bonding strength.

As shown in Figs. 9 and 10, for every matrix and heat treatment condition, the ultimate compressive strength of the pitch-based fiber composite was lower than that of the PANbased fiber composite. Although no reaction products were observed in the pitch-based fiber composites and the interfaces were smooth (Figs. 4(c) and (d)), the interfacial bonding in the composites would be strong as well as that in the PANbased composites, based on their fracture features (Figs. 11 and 12). However, the fiber-delamination in the longitudinal direction was frequently observed on the fracture surfaces of the pitch-based fiber composites (Figs. 12(c) and (d)). The highly-developed graphite crystallites in the pitch-based fiber would produce a strong anisotropy in the properties, as already mentioned. These findings indicated that the strength in the transverse direction of the pitch-based fiber is not enough to increase the strength of the composites, especially when the matrix strength is high. It can be concluded that the reinforcing effect of the pitch-based fiber was clearly observed only in the pure aluminum at $523 \mathrm{~K}$, and the effect was not observed in the AC8A alloy. On the other hand, this pitchbased fiber has an outstanding effect to decrease the thermal expansion $^{18)}$, increase the thermal conductivity ${ }^{20)}$ and improve the machinability ${ }^{21)}$ and wear resistance ${ }^{22)}$ of the AC8A alloy. In order to utilize this composite as a wear and heat resistant material, the high temperature strength should be improved. For example, the hybrid aluminum composite, which is reinforced with a proper volume fraction of an alumina fiber and the pitch-based carbon fiber, would be a possible way to improve the high temperature strength, while retaining the preferable properties mentioned above.

\section{Conclusions}

The present study has led to the following conclusions.

(1) $\mathrm{Al}_{4} \mathrm{C}_{3}$ was formed at the interface between the PANbased fiber and pure aluminum, while no reaction products were observed between the fiber and AC8A alloy. No reaction products were observed in the pitch-based carbon fiber composites.

(2) The reinforcing effect of the PAN-based fiber was observed in the pure aluminum at every temperature and in the as-cast AC8A alloy at $523 \mathrm{~K}$, while it was not observed in the as-cast AC8A alloy at ambient temperature and T6-treated alloy at every temperature. The ultimate compressive strength of the PAN-based fiber composite was greater than that of the pitch-based fiber composite for every matrix and temperature. Degradation in strength of the composites due to the heat treatment did not occur for the PAN-based fiber/AC8A alloy composites but occurred for the PAN-based fiber/pure aluminum composites.

(3) The reinforcing effect of the pitch-based fiber was clearly observed only in the pure aluminum at $523 \mathrm{~K}$. Degrada- 
tion of the strength due to the heat treatment was hardly observed for the pitch-based fiber composite. Although the fracture feature of the pitch-based fiber composite revealed that the interfacial bonding in the composites was as strong as that of the PAN-based fiber composites, very thin fibers were frequently observed on the fracture surfaces, indicating that the fiber oriented transverse to the stress direction would cause delamination between the highly-developed graphite crystallites in the fiber leading to the low reinforcing effect.

\section{REFERENCES}

1) “Torayca T300 Data Sheet”. Toray carbon fibers America, Inc. http:// www.toraycfa.com/pdfs/T300DataSheet.pdf (accessed 2016-12-29).

2) "Product Catalogue". Toray Industries Inc. http://www.torayca.com/ download/pdf/mildfiber.pdf (accessed 2016-12-29).

3) "Data sheet for GRANOC". Nippon Graphite Fiber Corporation. http://www.ngfworld.com/en/en_skill.html (accessed 2016-12-29).

4) Y. Arai: Nippon Steel Technical Report 59 (1993) 66-70.

5) J. Gu, X. Zhang, M. Gu, Z. Liu and G. Zhang: Mater. Lett. 58 (2004)
3170-3174.

6) B. Wielage and A. Dorner: Surf. Coat. Tech. 108-109 (1988) 473-478

7) L. Liu, W. Li, Y. Tang, B. Shen and W. Hu: Wear 266 (2009) 733-738.

8) S. Li and C. Chao: Metall. Mater. Trans., A 35 (2004) 2153-2160.

9) K. Yamada, S. Sekiguchi, T. Hanamura and T. Inoue: J. Jpn. Inst. Metals 59 (1995) 1108-1117.

10) T. Suzuki and H. Umehara: Carbon 37 (1999) 47-59.

11) T. Etter, P. Schulz, M. Weber, J. Metz, M. Wimmler, J.F. Löffler and P.J. Uggowitzer: Mater. Sci. Eng. A 448 (2007) 1-6.

12) X. Qu, L. Zhang, M. Wu and S. Ren: Mater. Int. 21 (2011) 189-197.

13) M. Yang and V.D. Scott: J. Mater. Sci. 26 (1991) 1609-1617.

14) M. De Sanctis, S. Pelletier, Y. Bienvenu and M. Guigon: Carbon 32 (1994) 925-930.

15) W. Lacom, H.P. Degischer and P. Schulz: Key Eng. Mater. 127-131 (1997) 679-686.

16) H. Miyahara, Y. Maruno and K. Ogi: Mater. Trans. 46 (2005) 950-958.

17) M. Gupta and M.K. Surappa: Mater. Res. Bull. 30 (1995) 1023-1030.

18) K. Asano: Int. J. Cast Met. Res. (in peer-review).

19) M. Mizumoto, T. Murano and A. Kagawa: Mater. Trans. 43 (2002) 2629-2634.

20) K. Asano: Int. J. Cast Met. Res. (in peer-review).

21) K. Asano: Mater. Trans. 57 (2016) 1300-1304.

22) K. Asano and M.F. Zainuddin: Mater. Trans. 58 (2017), in press. 